\title{
Os silêncios da narrativa
}

IRENE CARDOSO

Ao Salinas, in memoriam

RESUMO: Leitura da narrativa Retrato calado, de Luiz Roberto Salinas Fortes, que procura reconstruir alguns de seus traços, reconhecidos a partir de uma possível "experiência de leitura".

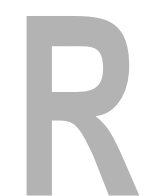

etrato calado 1 é o título do texto de Salinas, enigmático porque construção que remete simultaneamente a dois silêncios: àquele que lhe "roubou a palavra, comeu a fala, cortou a língua" (p. 103) - o calar-se (tacere) - e o silere, o silêncio reencontrado na escrita "ainda uma nova forma de silêncio", como diz - o "único recurso", o "antídoto", o "alinhamento das palavras", a "inscrição como resposta" (p. 102).

Retrato calado é o modo de nomear a figuração que vai sendo construída no texto, a partir das diversas posições do sujeito narrativo, que resulta da possibilidade deste encontro do silêncio - tempo de formação da palavra e tempo para que ela possa se escutar no que diz (Cardoso, 1997, p. 180). Trabalho insistente e doloroso que produz o pensamento e a fala sobre o que está calado - "e eu aqui insistindo sobre tão insignificantes eventos, querendo me fazer de importante (...) não riam, por favor, pois a dor é séria" (p. 105). "É aqui, neste exato momento, que se trava a luta. Cada traço inscrito é um tiro, é um golpe (...) cada linha é lança, gume, faca que penetra na carne dura do inimigo vário. Plural..." (p. 102).

Insistência narrativa que vai deslocando o calado - posição do que não se compreende e a partir da qual sobrevêm os delírios que fazem esquecer -, que se defronta com o real, "este real que parece um delírio circular, ele

UNITERIMOS:

narrativa, memória, silêncio, tortura.

Este texto foi lido na Mesa de abertura do Colóquio Rousseau Homenagem a Luiz Roberto Salinas Fortes, no Departamento de Filosofia da FFLCHUSP (17/11/1997). O livro a que se refere este texto foi publicado postumamente em 1988, a partir dos manuscritos deixados por Salinas, que faleceu em 1987.

Professora do Departamento de Sociologia da FFLCH-USP 
também" (p. 103), e através da memória - "confissões" - procura "não deixar que tudo se perca, se evapore", no "esforço de compreensão" de si mesmo e da "época complicada, labiríntica" (p. 89).

Retrato calado inscreve-se no difícil gênero das narrativas que tematizam a impossibilidade mesma de narrar a partir de situações extremas, na não garantida busca de uma compreensão, do que talvez, no limite, não seja comunicável, porque "o horror, por sua natureza mesma, nos empurra para os confins da linguagem, para aquilo que pode ser vivido sem poder ser dito" (Bernardi, 1988, p. 40).

"Há algo que se rompe, pois não é impunemente que se passa pela experiência da prisão" e da tortura. E Salinas continua: "A passagem pelos subterrâneos do regime, o contato com o avesso do milagre, eram, nestas condições, a ocasião para um aprendizado tão importante quanto inútil, pelo menos durante muitos anos. Mas, de qualquer maneira, experiência decisiva no interior da selvagem fenomenologia. Guinada. Depois dela, depois de termos ingressado no espaço da ficção oficial, passávamos para outra figura do espírito, para o delírio, em cujos breus parecem comprometidas as fronteiras entre o imaginário e o real. Tudo teria sido então pura ficção? Tudo ficará por isto mesmo? A dor que continua doendo até hoje e que vai acabar por me matar se irrealiza, transmuda-se em simples 'ocorrência' equívoca susceptível a uma infinidade de interpretações, de versões das mais arbitrárias, embora a dor que vai me matar continue doendo, bem presente no meu corpo, ferida aberta latejando na memória" (p. 29).

É ele próprio quem se pergunta: "Poisé. Por que escrevo tudo isso??? Por que relembrar águas passadas e repassadas e bem passadas? Qual a importância, afinal, do gênero - como chamá-lo? - 'memorial'?' (p. 80).

"A única coisa que sou capaz de dizer no momento é que se as escrevo - as memórias - é para dar a mim mesmo, conceder-me em benefício próprio, uma 'anistia ampla, geral e irrestrita', já que ninguém me concede. Por que não? Quem impede? Uso deste espaço para não deixar que tudo se perca,se evapore. E continuo dizendo dessa forma canhestra e imprecisa, infiel e abstrata. O fato é que tudo mudou, que era o mundo antes, o meu, bem diferente. $\mathrm{E}$ tudo vai ficar por isto mesmo? Eles torturaram, mataram, destruíram, tripudiaram, achincalharam, humilharam e continuam aí, juízes finais, são

1 Diante de uma narrativa, como Retrato calado, de Luiz Roberto Salinas Fortes, que nasce de um silêncio e é por ele construída, não cabem a análise nem o comentário: apenas a "experiência de leitura", que reconstrói alguns de seus traços através da repercussão naquele que lê. eles que decidem o que é certo ou errado, o que é bom ou mau. Mas esqueçamos as transas 'morais' e retornemos à descrição dos eventos” (p. 80-81).

Memorial, memórias, confissões, autobiografia?

Como constituir um sujeito narrativo a partir de uma "vida cesurada", como diz, "corte (...) certamente fundo, bem no fundo" (p. 39). Como narrar, se a consciência tem dificuldade em reviver, em evocar com exatidão o primeiro ato do pesadelo, e se esforça, ao contrário, por mantê-lo "recalcado, fora de seu âmbito?" (p. 29). Retrato calado colado na experiência vivida no "inferno" que produz a indistinção entre o real e o imaginário. Qual a possibilidade de uma narrativa a partir da "erosão do sujeito desfalecente", de um "eu (...) demo- 
lido" pela "lógica incontornável" das circunstâncias? (p. 50). "Como contornar a lógica da tendência se o sabotador, com toda a sua malícia, instalou-se dentro da cabeça, enfiou-se no interior do interior, sugando os esforços e comprometendo a objetividade do pensamento?" (p. 100). Como fazer fluir a memória se as grades estão nela ainda "duramente plantadas", "grades que continuam imaginárias, a me comprimir o cérebro?” (p. 100).

É desse modo que a narrativa vai se construindo, tematizando a sua própria impossibilidade. As questões de modo angustiado e doloroso vão emergindo sem nenhum tipo de censura ou complacência, especialmente em relação a si próprio, a partir do silêncio, reencontrado na escrita.

Retrato calado, a narrativa que tematiza a impossibilidade da narrativa, assume o risco da construção literária da experiência vivida que não pode ser dita - a literatura falando daquilo que se cala (Sarlo, 1997, p. 27-28). É necessário então o registro rigoroso da experiência, como diz Salinas "da sua descrição, da constituição do material fenomenológico, da sua transcrição literária. Contra a ficção do gênio maligno oficial se impõe um minucioso relato histórico e é da boa mira neste alvo que depende o rigor do discurso" (p. 29).

É desta posição que a narrativa vai se construindo, a da "boa mira", que se move e se desloca permanentemente ao longo do texto, sem se fixar num fio condutor cronológico, dando lugar aos vários tempos da experiência que se entrecruzam nas suas diferentes intensidades - tempo vazio, tempo da morte, rotina da sobrevivência, abismo do tempo, intervalo, outro tempo, tempo acelerado, tempos difíceis, espera - e que vão fazendo falar os até então mudos sujeitos que não podiam emergir das suas posições armadas de fora, armação que no entanto cala fundo, retratos calados.

Narrativa ofegante e entrecortada que expressa a impossibilidade de compreender os nexos entre as coisas e a própria condição de Coisa: "Que me espera agora? Que crimes cometi, afinal?" (p. 37). "Vestido. De novo Gente. Ou quase. Coisa, depois de tudo o que acontecera, que eu já nem julgava mais possível" (p. 44).

Impossibilidade de compreender o ritmo delirante da realidade, que não pode ser narrado a partir de nenhuma linearidade: "este real que parece um delírio circular, ele também” (p. 103). Delírio circular do real, imagem que convoca a "visão de espanto", os "dedos remos", a "caneta âncora para navegarem no mar das coincidências" (p. 103). "Jogo incessante de imagens que se superpõem" (p. 92), "sem a mediação-deformação do narrador historiador" (p. 91), como diz na análise que faz do filme visto em Paris, no tempo agora livre da nova vida das ruas estrangeiras, mas familiares, na carta ao amigo transcrita/inscrita no texto. A inserção/inscrição não gratuita da análise do filme na narrativa induz o leitor a vê-la naquele registro do jogo incessante de imagens que se superpõem, que é, no entanto, ainda, como diz a respeito do filme, "fruto da mais inteligente construção" (p. 91).

Sem a mediação-deformação do narrador historiador a narrativa vai se construindo através de um sujeito que constantemente se depõe de suas posi- 
ções e vai cedendo lugar a um outro que surge quando, como diz ainda Salinas a respeito do filme, "de repente, o espectador sente de maneira intensa como sendo o lugar do trabalho do cinegrafista", quando ainda o "jogo incessante de imagens que se superpõem, se neutralizam num comentário, em que é possível distinguir vários patamares expressivos" (p. 92). Um "achado narrativo" (p. 93) do filme, como diz, que parece ser também o da sua própria narrativa.

Lugar do trabalho insistente, da insistência narrativa a partir do qual se pergunta: "Como deixar de me pôr totalmente em questão, ali diante de tão vil desfecho? Como não me perguntar pelo sentido de todo esse movimento passado, atendo-me exclusivamente à fria descrição dos eventos? Como não mobilizar o espanto diante de tantos significantes de consequiências tão devastadoras?"'(p. 37).

Posição do sujeito narrativo, que emerge da "boa mira" móvel, aqui e ali no texto, diante das demais posições marcadas pelos "significantes" devastadores, pelo "destino" que "ia se decidindo misteriosamente lá fora" (p. 86), pelo "Mar das Coincidências" (p. 103-104), no qual se vê "envolvido, ilhado e circundado por acasos mais pesados e fatais do que qualquer necessidade" (p. 104).

Cena Primitiva e Repetição: modos como o narrador nomeia a ordenação possível do relato destas experiências a serem decifradas. Esta ordenação não pode ser a da ordem cronológica, embora o narrador se angustie por retomá-la de algum modo: "Não confundamos as coisas e tentemos reconstituir a chamada ordem cronológica, pois Cronos é um deus muito poderoso e voraz que nos consome tanto que já não podemos mais deter o fluxo, o fluxo tão sonhado que de repente arrebenta" (p. 86). DEIC, OBAN.

Duas prisões em 1970, outras duas em 74. OBAN, DOPS;

Cena Primitiva se abre no "velho edifício do largo General Osório", o DOPS, meses depois dos dez dias de detenção na OBAN. Mas agora as coisas seriam bem diferentes e logo, "logo seria dado ao protagonista que vos fala a ocasião única, o privilégio imerecido de vir a conhecer o famoso instrumento de tortura já há muitos e muitos anos corriqueiramente utilizado por nossas forças policiais em toda a vastidão do território nacional" (p. 9).

"Só quando chegamos percebo, de repente, o que me espera e entendo o sorriso. É que o tal do magricela nervosinho e gozador me mandara carregar, envolto em jornais, para disfarçar, nada mais, nada menos do que o aparelho de choque, a cujas iluminações, dali há pouco, paudeararizado, viria eu a ser submetido graciosamente. $O$ grupo explode em gargalhadas quando o pacote é desembrulhado, deixando a descoberto aquela sorte de pequeno realejo, cubo de madeira com uma manivela pendurada de um dos lados. E eu, atônito, catatônico, arremessado de repente em meio ao inferno, transferido de súbito para esta dimensão nova onde tudo se passa velozmente, embora dure uma eternidade e embora se propague pela eternidade afora" (p. 9-10).

Na reconstrução da Cena, o jogo rápido de alternância das imagens, que se traduz nos modos diversos de enunciação possíveis: o sujeito narrativo 
oscila entre posições que dão origem ora a uma fala que está colada à Cena, ora àquela do distanciamento em relação a ela, que parece tão penoso construir. Oscilação entre um eu colado e um ele que produz a distância, que expressa literariamente a quase que impossibilidade de reconhecimento da Cena, do seu absurdo. Não é possível que aquele personagem da Cena seja eu, e no entanto ele é a minha irredutível condição.

" $\mathrm{Nu}$, completamente nu. Obrigam o paciente a sentar no chão. Amarram-me as mãos, que protegem com uma cobertura de pano, uma contra a outra. Forçam-no a manter os joelhos unidos, dobrados contra o peito e envolvidos pelos braços amarrados. No vão entre os braços e o joelho enfiam uma barra de ferro e penduram-na - penduram-me - em dois cavaletes. Rápidos, eficientes, bem treinados" (p. 10). E vão fazendo "funcionar o aparelhinho que eu mesmo carregara como perfeito idiota" (p. 11). "Com seu paciente trabalho junto à manivela, o hílare servidor, arrebatado por formidável furor científico, ia buscando estabelecer a verificação empírica da veracidade das proposições que eu formulava e respondia e vomitava em meio à dor, ao pânico e à reconfortante revolta que não mais me abandonaria" (p. 12).

Abertura da Cena Primitiva e, como diz, "repetição monótona da macabra cena inaugural do espetáculo pirotécnico do Brasil grande do fim da década de 60 e do começo dos 70” (p. 11).

As questões vão se colocando, "perguntas que não deixam de se impor e insistir o tempo todo" (p. 12), deslocando os sujeitos emudecidos, confrontando o real e o imaginário, dissolvendo os delírios num movimento de entrelaçamento da busca de uma consciência de si, a partir da vida cesurada e de uma consciência do real para além dos seus também delírios circulares.

Como diz: "Tais perguntas ou dúvidas, talvez suspeitas ou supérfluas aos olhos do entendimento, só se justificam nesta sua configuração hiperbólica, se o que pretendemos é justamente nos dedicar às questões radicais, ou se o que nos inquieta é a radicalização das questões que prolongam no espaço da reconstituição a Questão primeira, tornando tão difícil a exposição dos eventos e toda a lítero-analítica a que nos conduz obrigatoriamente a necessidade do exorcismo" (p. 13).

Diante da situação da tortura no DOPS se pergunta: "Terei falado demais?, herói ou covarde? É certo que o herói perfeito jamais colocaria tais questões, o que significa, talvez, que pelo simples fato de enunciá-las já me denuncio como Guerreiro pouco valente. Ou me desqualifico para as finais da copa do heroísmo" (p. 12). Situação que repete a da OBAN, meses antes, diante da exigência da "colaboração", que tortura o "espírito até hoje" embora sem "consequiências mais dramáticas": "Como agir? Que dizer? Nada falar, tal como o vietcongue?" (p. 20).

"Deveria ter saído do país? Não sei. Partido para a clandestinidade e me comprometido com a luta armada, desta vez para valer? Talvez. Mas, que perspectiva nos oferecia, que não a suicida, a ação violenta contra o regime? Não estaríamos antes obrigados a resistir sobrevivendo, do que a morrer 
lançando a força contra a força neste combate desigual (...)?” (p. 33-34).

Radicalização das questões que incide sem complacência sobre si próprio, mas também pode discriminar o tipo de lógica da tortura que leva aqueles que são a ela submetidos, e que não são inteiramente destituídos da própria subjetividade, a se constituírem nas figuras do herói ou do traidor, na polaridade entre heroísmo e vergonha, lógica incorporada em certa medida pelos próprios torturados e grupos aos quais pertenciam.

Questões radicais que podem pensar "os delírios circulares do real", sem nenhum tipo de condescendência com o regime, com a sua aceitação pela sociedade e também com o "militantismo radical".

"Lá fora, o melhor dos mundos, como se nada tivesse acontecido. Os generais prosseguiam, meticulosos, na patriótica azáfama; o povo brasileiro deixava-se salvar ao som estridente do 'eu te amo meu Brasil' e se preparava para o Grande espetáculo, enquanto seu pacífico esquadrão [não o da Morte], sob o comando de Pelé e Tostão, aprestava-se para as próximas batalhas, que as Tvs transmitiriam do México" (p. 33). "Regime hipócrita e todopoderoso de um lado. De outro, grupos de combatentes decididos mas amadorísticos, com escasso apoio popular, cegos pelas suas estreitas categorias teóricas ou pela fé ingênua nas virtudes do militantismo radical, acreditando que um assopro seria suficiente para conduzir à conflagração geral, à avassaladora explosão das massas enfurecidas, pondo abaixo o edifício da iniqüidade" (p. 34).

"Tomar consciência do real". "Aceitar calmamente, este real que parece um delírio circular, ele também": o "Mar das Coincidências", o dos "acasos mais pesados e fatais do que qualquer necessidade" (p. 103-104), do qual é preciso emergir.

Repetição-modo como nomeia outro movimento da narrativa - que produz "a sensação de destino", que "converte (...) a vida em morte" (p. 86).

"Meu destino ia se decidindo misteriosamente lá fora" (p. 86). "Pois é, depois da OBAN e do DOPS, o DEIC. (...) Não imediatamente: quatro anos depois" (p. 77). E ainda novamente a OBAN.

Como reconstruir o tempo, como interromper o tempo da repetição, delírio do tempo? Como inscrever as experiências que não têm registro, que "teórica e oficialmente nunca existiram" e "residem no território da ficção"? (p. 81).

Entrecortada pelas questões, a narrativa vai se construindo a partir mesmo dos cortes - que outro modo? - da vida cesurada, do corte bem fundo, bem no fundo.

"Como manter a lucidez em meio à complexidade? Como proceder à leitura do texto denso, desvendar os liames sutis, os vínculos que se entremostram, como evitar as pistas falsas, como fugir à tentação preguiçosa da facilidade? Às vezes a relação parece nítida, a correlação rica em promessas de resultados fecundos. Da minha janela, olho o muro em frente, do outro lado da rua [naquela época eu passava horas e horas em contemplação do muro da rua em frente, sentado em frente à janela] e sonho com o mundo em 
que não haveria polícia. Mas ela insiste em me acompanhar. Lembro-me bem daquele dia em que olhava pela janela e contemplava o muro cinzento em frente, do outro lado da rua. De repente eles chegaram, de novo. Rádiopatrulha, vermelho e negro, dois guardiões. Estacionaram o carro na entrada da vila e um deles desceu. Teria sido um sonho? Até hoje não sei muito bem. Teria sido projeção da megalomania que de mim se apoderara e que me dotara do sentimento permanente de trazer guardada dentro de mim a mensagem fatal, definitivamente fatal para a ordem vigente? Mas naquele momento nada parecia mais real" (p. 100).

Repetição ainda, mas também agora, a possibilidade do "exorcismo", como diz, "que se renova a cada instante, a cada hora, a cada dia, a cada semana, a cada ano, a esperança que rejuvenesce, de quebrar as grades, voar, essas grades imaginárias" (p. 100).

À imagem do muro cinzento em frente, que contempla sentado junto à janela, se superpõe a do "muro alvo", no jogo incessante delas que atravessa a narrativa: "Aqui no meu muro alvo, imitando o mestre, as confissões. Tramadas no inferno e recapturadas à luz das ruas ensolaradas, vestidas de cor e corpo completo sonhado, não mutilado (...) Os inimigos nos olharão com desprezo: coitado, dirão, até hoje ainda falando de tudo isto. E os traços da aventura menor já foram talvez até apagados dos arquivos, borrados dos anais e certamente suplantados por milhares de outras histórias mais excitantes que se repetem diuturnamente e eu aqui insistindo sobre tão insignificantes eventos" (p. 105).

Insignificantes eventos, que no entanto calaram fundo, bem no fundo, cuja intensidade só pode ser reconstruída a partir de um outro movimento da insistente narrativa, inter-calado entre os outros dois, Suores noturnos, que reabre os sentidos, já não fechados, de Cena primitiva e repetição.

Suores noturnos são páginas de um Diário escritas por Salinas em 59 e 60 - num quarto de pensão em São Paulo, vindo da "interiorana cidade natal", como diz - transcritas e inscritas na narrativa Retrato calado.

"Sinto-me só. Fora do mundo. Como personagem do livro 'The Outsider' de Colin Wilson (...). Diz este autor: 'Quem sou eu? Eis aí o problema essencial do Estrangeiro'. E eis aí porque me identifico.

$\mathrm{O}$ futuro me parece um abismo. Tenho medo. Acho que sempre fui assim, pensando bem. O mundo sempre me pareceu hostil (...) Não sei onde é o meu lugar certo. Sempre fiquei meio de fora, como um estranho, mesmo entre os amigos mais próximos.

O futuro está aí, ao meu lado, imenso, incerto, desconhecido. É preciso decidir logo, agora mesmo. É preciso me libertar destes naufrágios quotidianos. Devo escolher um caminho e sofrer até o fim as consequiências dessa escolha (...) meu destino é o de refletir sobre mim mesmo e o mundo.

Devo me libertar antes de tudo da tirania do outro. Mas para isto é preciso, talvez, mergulhar cada vez mais na solidão.

Sinto-me limitado, tenho dúvidas acerca das minhas possibilida- 
des. Que fazer? Antes de tudo, quero enxergar claro. Lucidez: eis a principal exigência" (p. 64-5).

Destino, Lucidez, Medo, inquietação diante da "radicalização das questões", aqui como lá.

Destino: "acabo de ler 'L'Espoir' de André Malraux. Belo, belo. Diz ele que a 'possibilidade infinita' do destino dos homens é mais 'inquietante' do que 'sua presença sobre a terra"” (p. 67).

Lucidez: "Por que escrevo? Alinhar palavras, construir frases (...) de que adianta tudo isto? As coisas continuam a deslizar pelo abismo do tempo afora.

(...) Não sei por que escrevo, mas não importa. Vou continuar escrevendo, vou me submeter às palavras e deixar que elas corram livremente. Alguma coisa vai ser retida, talvez, quando futuramente eu procurar fazer um "balanço vital"' (p. 67-68).

Medo: "Tenho me lembrado muito ultimamente daquele antigo, digamos, surto neurótico infantil. A mesma cena repetiu-se durante muitas noites seguidas (...) De repente, uma horrível visão me atacava e me botava em verdadeiro pânico. Era a seguinte: eu me via, de repente, morto, dentro da sepultura. O que mais me aterrorizava era o fato de eu não compreender como poderia a alma - que me haviam ensinado imortal - desprender-se do corpo, libertar-se dele. Acreditava que isto não fosse possível, imaginava então que continuaria consciente, (...) na eterna escuridão tenebrosa da sepultura (...) Até mesmo os terrores do inferno me apareciam como menos terríveis do que a perspectiva de uma prisão perpétua dentro da cova (...). Fazia esforços sobre-humanos para compreender o enigma, suava e estremecia, e o fracasso da investigação obscura me arrancava lágrimas de pânico" (p. 65-66).

Retrato calado, a narrativa que não se fecha. Que não imobiliza a existência num "sempre passado", morto, mas se constitui em "obra de uma memória viva, vital, que quer e pode recuperar o tempo em seu próprio movimento" (Blanchot, 1997, p. 237). A construção insistentemente retomada, a forte impressão causada pela leitura de Suores noturnos, mas também registrada por Salinas, no que escreve como acréscimo posterior, quando da preparação dos originais, referindo-se à noturna cena relatada: "mas o episódio contém certamente muito material, traz certamente oculto nele muitas pistas para a explicação do ulterior evoluir. A ele devo retornar. E insistir. Tentar decifrá-lo" (p. 67).

Narrativa que não se fecha, mas que fechou a vida de Salinas. Como ele disse, ainda, no Diário, referindo-se à morte recente de Camus - "este meu amigo íntimo": "essa figura foi ludibriada, sua vida convertida em "destino', como dizia Malraux, porra, como a morte é uma coisa besta" (p. 70). 
CARDOSO, Irene. The silences of narrative. Tempo Social; Rev. Sociol. USP, S. Paulo, 10(1): 9-17, may 1998.

ABSTRACT: A reading of Luiz Roberto Salinas Fortes' narrative "Retrato Calado" based on the reconstruction of some of its characteristics through a "reading experience".

UNITERIMS: narrative, memory, silence, torture.

\section{REFERÊNCIASBIBLIOGRÁFICAS}

Bernardi, Ricardo. (1988) Psychanalyse et étayage sociale. Patio, 11 ( La terreur subjective), Paris, Éditions de l'Éclat.

BlanchOt, Maurice. (1997) Olhares de além-túmulo. In: A parte dofogo. Rio de Janeiro, Rocco.

CARdoso, Irene. (1997) A narrativa silenciada. In: CARdoso, Irene \& SilveIRA Paulo (orgs.). Utopia e mal-estar na cultura: perspectivas psicanalíticas. São Paulo, Programa de Pós-graduação em Sociologia da USP/Hucitec.

Salinas Fortes, Luiz Roberto. (1988) Retrato calado. São Paulo, Marco Zero.

SARlo, Beatriz. (1997) Paisagens imaginárias: intelectuais, arte e meios de comunicação. São Paulo, Edusp. 
